\title{
Creativity, Wicked Problems and the Contemporary PhD
}

\author{
Josie Arnold \\ Swinburne University of Technology, Melbourne, Australia \\ Email: jarnold@swin.edu.au
}

Received 14 July 2016; accepted 28 August 2016; published 31 August 2016

Copyright (C) 2016 by author and Scientific Research Publishing Inc.

This work is licensed under the Creative Commons Attribution International License (CC BY). http://creativecommons.org/licenses/by/4.0/

(c) (i) Open Access

\begin{abstract}
In this paper, I survey the challenges the creative and contemporary PhD make to the academy. I look at the scholarship entailed in creative production and in identifying and working with wicked problems as having similar attributes contributing to the need to create new PhD models. Traditionally, the PhD has been a preparation for a career in the academy, with scholars undertaking it so as to show their capacity to identify a research gap in their area, to develop a research question from that and to build a major and new contribution to knowledge in a written submission of some 100,000 words. This traditional model is based upon the certainties of scholarship within enlightenment ideals of science. These have delivered us great strides in many areas of medicine and science and have also come, because of their productivity, to dominate the arts, particularly the social sciences and psychology. Whilst its value should not be debased, this enlightenment model has been challenged from such different areas of scholarship as creative production and wicked problems. The core ideas in this paper are how we might utilise creativity and emerging ideas of wicked problems to debate the importance of understanding the contemporary PhD.
\end{abstract}

\section{Keywords}

Creative Productions, Wicked Problems, PhD Today

\section{Introduction}

Today, many people are undertaking a $\mathrm{PhD}$ so as to bring to their work a more scholarly appreciation, to bring together theory and practice to enrich their knowledge base, and to make scholarly contact with others in their area. They may also wish to bring academic rigour to their thinking and insights and also to alert the academy to emerging ideas and problems. Today, also, most governments are endeavouring to increase PhD studies so as to nurture talent to provide intellectual leadership in a world of increasingly complex global challenges. The con- 
temporary $\mathrm{PhD}$ recognises this and sees that such academic insights will come from different innovative projects that may vary from traditional $\mathrm{PhD}$ models. Factors that place pressure upon the traditional model include employment opportunities, the greater diversity of the student cohort including gender, age, ethnicity, work experience, and also part-time status. In a similar vein, the creative $\mathrm{PhD}$ challenges static models of scholarship, recognising narrativity and practice led research (PLR) and bringing practice to the academy.

There are new expectations about the use and outcomes of the contemporary $\mathrm{PhD}$ that "require researchers to have additional and different skills such as a more sophisticated approach to research management, an ability to cross discipline boundaries and an understanding of the pathways through which research can have an impact" (The Changing PhD Group of Eight discussion paper March 2013, p. 5) [1]. Such new expectations should not be confined to meeting the challenges of wicked problems, but can be correlated with creative PhDs such as PLR artefact and exegesis models.

The contemporary $\mathrm{PhD}$ can provide pathways that don't conform to traditional models of academic use and disciplinary knowledge but that apply research skills in other ways. Such a $\mathrm{PhD}$ model will include employment projects, coursework and other novel options and inputs. It will move more into action based upon research and reflection and will build upon the Australian Qualifications Framework (AQF) [2] that "requires graduates to have undertaken a program of independent, supervised research" that is subject to independent examiners of international standing. Many other countries also formally examine the student performance through a personal spoken defence of the dissertation. It may be that the contemporary $\mathrm{PhD}$ would add such a personal communication skill to the project, thus setting an international component.

Because so much knowledge content is changing so rapidly and is so readily available digitally, the contemporary $\mathrm{PhD}$ could connect scholarly knowledge with practical work experience to take into account the changed external business and cultural global environment. This arises from a diverse student population that may have generalist skills development rather than focussed specialisation, as the Group of Eight considers that: "there is also a need for broad, strategic, and creative understanding flowing from the application of high-level analytical and conceptual skills that build on broad, cross-disciplinary knowledge" (19) [1]. Combining educational and other experiences of knowledge construction calls for complementary higher degree structures as well as lifelong learning educational services so as to "recognise the importance of contingency in everyday life" as "the unforeseen is always with us" (20). This calls for higher education degrees that are creative, flexible and adaptable.

Ways of knowing have been broadened in scholarship as the academy accepts and utilises what Martin Heidegger called his field path or der feldweg that describes ways of framing, knowing and being, looking and listening, analysing, being-with, proposing, acting and reflecting, constructing, performing, deconstructing, and learning (see Copeliovitch, 2015) [3]. Although many scholars are also practitioners, this was not a central concern for the academy, in particular for $\mathrm{PhD}$ candidacy until the late 20th century. Again traditionally, creative practice has been the object of research rather than given a place in scholarship as research itself. The contemporary $\mathrm{PhD}$ challenges this, as well as confronting wicked problems, and it also acknowledges the importance to scholarship of creative productions.

In this paper, I bring together these two contemporary $\mathrm{PhD}$ models to open further the discussion about new ways of developing creative and contemporary knowledge and scholarship.

\section{The Creative PhD}

The model of the artefact production and the exegetical framework challenges traditional models. The PhD in writing by artefact and exegesis has been amazingly successful in bringing practitioner knowledge into the academy. It has followed the methodology of PLR in scholarship. This is "the "how' of research" that "contains the limits and holds the research strands in place as the researcher weaves the textures of new knowledge" [4]. This describes the narrative self-reflective and scholarly core of PLR.

Writing, being textuality and discourse, encompasses all forms of textual production. For Elizabeth Grierson and Laura Brierley (2009) [4] such PLR academic knowledge encompasses "fine art, photography, theatre, music design, dance and film" (3). In discussing scholarship arising from practitioner-researchers, they aim to find "a way to legitimate the creative arts as a knowledge field equal to, but different from, the science" (4). They discuss PLRas developing a form of research that they describe as "about innovative thinking" that illuminates new knowledge. This will inevitably "involve imagination, invention, speculation, innovation, risk-taking" (6). Contemporary PhDs in the artefact and exegesis model demonstrate what Grierson and Brierley describe as 
needing "both the creative and technological know-how for the creative research production as well as the linguistic and theoretical acumen to write critically engaged and well-considered text" (7).

The exegesis is not a scholarly justification of the practice: it is better described as a framework or scaffolding that places the artefact within relevant scholarly discourse so that both together make scholarship. Led by the practice and the candidates' reflections upon their creative process, $\mathrm{PhD}$ candidates in this model identify issues and ideas for scholarly illumination in the exegesis. This leads to auto ethnographic insights that utilise the self as data.

The central significant question, then, draws on PLR to ask and answer the question: where am I in the text? (18). Elizabeth Grierson recognises that, while scaffolds are important:

...there is a particular kind of making and doing that is at stake in the realm of creative arts as a formalised research practice in the academic setting. It has the components of aesthetics and the potential always of making-new as a defining characteristic; taking intuitive leaps as it engages with its lineage of practice. Thus discourses of creativity are, by implication, generative (18) [4].

The scholar-practitioner, then, must offer more than the artistic or creative practice. Lesley Duxbury makes this useful distinction between the scholar-practitioner's work and art practice: “... research through art involves a self-conscious reflection... it needs to reveal its processes and illuminate the thinking that underpins the material manifestations and it needs to be experienced" (in Grierson \& Brierley 2009: p. 57) [4]. She discusses how "research is not complete until it involves someone to experience it" and how for her this means "inclusion of the viewer as an active participant in the work rather than as a passive observer" (59). This is true of the practice, and Elizabeth Grierson, Emma Barrow and Kipps Horn explicate that the scholarly framework must meet “... some external obligations of a scholarly kind, such as the requirement for identifiable questions, structures, scaffolds and frameworks" (in Grierson \& Brierley 2009: p. 129) [4].

\section{The Wicked Problem of the Contemporary PhD}

The traditional ways in which a singular candidate undertakes a major research project are challenged by imaginative transdisciplinarity. This is another change for most $\mathrm{PhD}$ structures in the academy to consider, involving as it may collective and holistic enquiry, international collaboration, and the ability to leave matters unsolved [5]. Descriptive relationships arising from discursive procedures are attributes of collaborative partnerships involving inter-institutional dialogue that may underpin the foci of the contemporary $\mathrm{PhD}$, leaving it difficult even to define clearly much less lead to a definitive research question and procedure appropriate to a $\mathrm{PhD}$ in the traditional mode [6]. Multiple alliances may be necessary between various partners in collaboration involving participatory information and research [7], and this means it is inappropriate that the individual researcher works alone, or even in a dedicated team, within a given scholarly template so as to define and research a given question or area. As so much data can now be put forward, a new term has been applied to research: the wicked problem, the absolute opposite of the tame one.

A tame problem is one that can be solved through the linear processes of traditional Enlightenment research models. In contrast, the wicked problem contains multiple possibilities. The wicked problem was first identified as such by Horst Rittel as containing some or all of the following 6 elements: the problem remains unable to be understood until the solution is developed; there is no finality but the solution is good enough; there is no objectively based right or wrong solution; every wicked problem is singular; every solution may lead to further wicked problems; there are no alternative solutions as there are so many potential ones a judgement call leads to a creative choice [8]. The tame problem, on the other hand, has a determined question; can reach a solution that can be objectively found to be right or wrong; belongs to a comparable class of problems solvable in similar ways; and can reach a focussed solution due to a limited number of possibilities [8].

The academic research project, like many organizations, may deal with wicked problems by setting about taming them! This cannot work because the problem is basically untameable. Complexity cannot be simplified, and the wicked problem involves at least, according to Conklin, social groups of researchers, design fragmentation and complex technical software. Such wicked problem research is of course undertaken in Universities, and it is the opening up of scholarship that such research indicates that is an important element of the contemporary $\mathrm{PhD}$. The challenge here is not to try taming the wicked problem so that the candidate can work within the expected $\mathrm{PhD}$ models. In this way, like the artefact and exegesis model, it draws practitioner knowledge into the academy. 
The contemporary $\mathrm{PhD}$, then, may offer candidature from practice, within external placements or as a result of industry grappling with wicked problems. In the latter case: "the context within which research takes place in business can be very different from that experienced while in an academic environment" [1]. The literature on this from the Group of Eight major universities in Australia acknowledges the requirement that all $\mathrm{PhD}$ research should "take place within an environment that itself demonstrates high standards" (50), but also stress that today it should be both inter and multidisciplinary. It should also provide "the potential to broaden the outlook of students, not least by creating opportunities and the need for trans-disciplinary networking, communication and learning" (50). They note cohort supervision rather than individual supervisors, a doctoral school, partnerships with end-users, and focus upon "Industrial Transformation Training Priorities" such as food, manufacturing, and other industry related research having "a strong focus on economic development and the generation of new jobs" (51). This involves co-mentoring and co-funding with industry partners, noted as unusual and difficult in Australia.

The contemporary PhD models would enhance this relationship and act to develop and strengthen "domestic and international linkages and networks" (52). This debate is not about the strength of current $\mathrm{PhD}$ programs and models but participates in:

an ongoing debate here as right around the world about the need for $\mathrm{PhD}$ programs, their purpose and effectiveness ... pressures for change are coming from the growth of $\mathrm{PhD}$ students, the increasing diversity of the $\mathrm{PhD}$ cohort and the problems of supporting part-time students who are often working off-campus and in non-academic environments (53).

It is also based on concerns about the employment possibilities for current $\mathrm{PhD}$ models and the need for "a system that extends beyond a narrow emphasis on training for a particular career to one which creates wellrounded, research-capable people able to market and apply their knowledge, skills and undoubted intelligence in a wide variety of contexts". This involves the creation of a "more diverse array of $\mathrm{PhD}$ programs" (54).

\section{The Contemporary PhD: An Overview}

Today most governments are endeavouring to increase $\mathrm{PhD}$ studies so as to nurture talent to provide intellectual leadership in a world of increasingly complex global challenges. The contemporary $\mathrm{PhD}$ recognises this and sees that such academic insights will come from different innovative projects that may vary from traditional $\mathrm{PhD}$ models.

Factors that place pressure upon this traditional model include employment opportunities, the greater diversity of the student cohort including gender, age, ethnicity, work experience, and part-time status. I would add to this the importance of bringing practice and studio work into the academy as is done through the artefact and exegesis model. This is appropriate within the contemporary $\mathrm{PhD}$ discussion as creative industries are major employers and contributors to national incomes across the world.

In Australia, for example, The Department of State and Regional development report "NSW Creative Industry: Economic Fundamentals", 2008 [9] defines creative industries rather traditionally as: advertising; architecture; design; visual arts; music; performing arts; publishing; film; television; radio electronic games "by their own scope rather than including" downstream stages...such as manufacturing, wholesale, distribution, retailing and second hand sales (2008: p. 7). The report goes on to state that: "The creative industry is a significant component of NSW's economy, employing over 5 percent of the workforce (of 150,000) Further, over the 10 years to 2006 , employment in the creative industry increased by 28 percent, against 13.5 percent for all industries" (2008: p. 8). It adds a further note that: "creative industry employment growth across Australia was marginally higher than for NSW" (2008: p. 10). So, creative industries employ large sections of the Australian community quite directly. The above report quotes the OECD estimates of cultural/creative contributions in Australia as $3.1 \%$ of the GDP, comparable with Canada at $3.5 \%$; France at $2.8 \%$; and the USA at $3.3 \%$ but outflanked by the UK at 5.8\%. (2008: p. 8). Such industries also engage informally and more indirectly many creative artists.

This paper, then, participates in discussing new expectations about the use and outcomes of the contemporary $\mathrm{PhD}$ that "require researchers to have additional and different skills such as a more sophisticated approach to research management, an ability to cross discipline boundaries and an understanding of the pathways through which research can have an impact" [1].

The contemporary $\mathrm{PhD}$ can provide pathways that don't conform to traditional models of academic use and 
disciplinary knowledge but that apply research skills in other ways. Such a PhD model will include employment projects, coursework and other novel options and inputs. It will move more into action based upon research and reflection and, in Australia, will build upon the Australian Qualifications Framework (AQF) [2] that "requires graduates to have undertaken a program of independent, supervised research" that is subject to independent examiners of international standing. Many other countries also formally examine the student performance through a personal spoken defence of the dissertation. It may be that the contemporary $\mathrm{PhD}$ would add such a personal communication skill to the project, thus setting an international component.

Because so much knowledge content is changing so rapidly and is so readily available digitally, the contemporary $\mathrm{PhD}$ could connect scholarly knowledge with practical work experience to take into account the changed external business and cultural global environment. This arises from a diverse student population that may have generalist skills development rather than focussed specialisation, as the Group of Eight consider that: "there is also a need for broad, strategic, and creative understanding flowing from the application of high-level analytical and conceptual skills that build on broad, cross-disciplinary knowledge" (19). Combining educational and other experiences of knowledge construction calls for complementary higher degree structures as well as lifelong learning educational services so as to "recognise the importance of contingency in everyday life" as "the unforeseen is always with us" (20). This calls for higher education degrees that are creative, flexible and adaptable. PLR artefact and exegesis PhD models certainly conform to this.

\section{Research Training and Training in Research through Practice, the Conduct of Research in the Job and in Business}

Creative industry models of $\mathrm{PhDs}$ undertaken by practitioners involve practitioner academics and candidates who come from such areas as design, drama, film, multimedia, dance, architecture and writing. Such a contemporary $\mathrm{PhD}$ model is not readily accepted, as clarifying practice as intellectual knowledge is a challenge in an academic environment that finds it difficult to align with practicum and that has not always seen practice as knowledge [10]. The model of PLR challenges such givens, rejecting the gate keeping that sees only traditional models of scholarly discourse as scholarly, nor does PLR see the exegesis as providing an academic element that acts to legitimise creativity.

Developing research capacities that are transferable is an essential element of the contemporary $\mathrm{PhD}$. The Group of Eight discusses the interesting idea that $\mathrm{PhD}$ research training is even more valuable in itself than the specific focussed research outcomes: a large claim as "the work of $\mathrm{PhD}$ students contributes a non-trivial proportion of the nation's total research effort and is performed cheaply" (33). Research training is flexible and can be applied and re-applied: it therefore contributes beyond the $\mathrm{PhD}$ production of knowledge and can move away from the expectation it is an entry into the academic work force.

According to the Group of Eight report [1]: "In Australia universities appear to employ less than 50 per cent of the $\mathrm{PhD}$ graduates ... and while demand from universities will continue to increase, so will demand from other sectors of the economy" (36). This is so because: "some people benefitting from $\mathrm{PhD}$ training will often move quickly to senior management and strategic positions that draw upon their demonstrated ability to think clearly, collect and assess evidence, develop and test hypotheses, draw conclusions and make decisions". For the Group of Eight this relies upon their ability to "move beyond the boundaries of their specialisation" (36). It is necessary, then, for contemporary $\mathrm{PhD}$ candidates to know how to "go beyond their narrow areas of specialisation".

If $\mathrm{PhD}$ training is to be effective, it has to respond to "wicked problems ... for which there is no single, simple or generally agreed solution and for which any intervention is likely to have multiple effects, some unintended, unwanted and even unpredictable" (35). This may lead to management rather than solution models. In this paper I suggest that working in new ways with wicked problems is another way to talk about creative practice which is always involved in developing new ways of thinking, seeing and expressing, so I see the two models as having much congruence.

In considering the contemporary $\mathrm{PhD}$, universities themselves must change from the traditional academic employment factor that has underpinned the relationship of the $\mathrm{PhD}$ project and training. Candidates must have access to the core competencies required in the modern workplace, and universities must decide how to facilitate this. The Group of Eight report states that such skills involve: "communicating and explaining to non-specialists and non-academics ... working on several projects at the same time ... working within stricter timeframes and often non-negotiable deadlines ... a very different research management regime in which factors other than 
academic excellence play a predominant role..." (38). For me, this also means accepting creative practicum as contributing to new ways of understanding and practising scholarship.

\section{Knowledge Creativity and the Contemporary PhD}

The current research environment in and outside the academy is extremely demanding and competitive. Employers are looking for high quality research:

... including the need to work and communicate effectively in mutidisciplinary teams; accepting the need for top down rather than bottom up (investigator led) research management that goes beyond research excellence to output (and outcome) focussed criteria; and factoring in cost and practicality, not just intellectual advancement, in research assessment processes." (Group of Eight Report: p. 39) [1].

The contemporary $\mathrm{PhD}$ will offer these skill sets, particularly those of working in and with a non-research oriented community. It is already extant in the skill sets developed in the complementary creative artefact and exegesis models of practitioner scholarship.

Creativity comes when we admit that we don't already know, but show that we are willing to try. Perhaps the most singular aspect of creativity is the capacity to accept difference in a way that enables us to learn rather than to re-practise old dogma. Gilles Deleuze sees learning as non-dogmatic, not as saying that everything is possible, but as saying that, like a learner-swimmer immersed in water, possibilities present themselves as to how to swim: "To learn is to enter the universal of the relations which constitute the Idea, and into their corresponding singularities ... To learn to swim is to conjugate the distinctive points of our bodies with the singular points of the objective Idea in order to form a problematic field" (in May 2005: p. 110) [11]. This concept of swimming provides an insightful and evocative metaphor for us to unpack. Relating it to creative production in the academy is both charming and multi-layered. Which of us has not felt swamped by information in this "information age"? Rather than drowning in it, creative knowledge in the broadest sense enables us to swim through it. This swimming is not just to prevent a drowning: it has in itself more depth than that. It brings ideas into being and/or into our own grasp so that we stay afloat and even move forward.

\section{Creativity in Scholarship}

The two models of the contemporary $\mathrm{PhD}$ that I have briefly surveyed here recognise the importance of uncertainty to scholarship, for “... all creativity is an experiment" (May 2005: p. 68) [11]. In this postmodernist moment, we no longer expect those attributes of scholarship that were once dominant. Perhaps the most structured of these was the opening, the beginning, the middle, and the end: the search and the solution. As in music, dance, visual representations especially painting, and even architecture, we no longer have the expectations that history and cultural metanarratives laid so heavily upon us. Today, as the text may be linear or elliptical, we have more open questions such as: where has the story begun/where does it go, and how does it get there? This is a significant attribute of contemporary and creative $\mathrm{PhDs}$.

Writing provides us with a good example of the contemporary $\mathrm{PhD}$ : it raises questions at both a personal and cultural level in a way that involves pleasure and pain as in play, and this is so for both the writer and reader. Certainly, writing and/as reading involves writer and reader in fantasy, fabrication and artifice, in both scholarship and uncertainty.

The focus of the contemporary $\mathrm{PhD}$ may well involve intransigent research questions and areas that need to be addressed by group interactions. Van Beuren et al describe them as "persistent despite considerable efforts to solve them" (2003: p. 193) [12]. They see this as particularly evident in policy problems arising from highly technical issues "in the fields of environment, health and safety" and state that this is so because they involve "a context of great uncertainty with regard to the nature and extent of the risks involved for individuals and society as a whole". Furthermore, of course, many of these problems are global in impact and call for considerable insight into and working with relevant interested and effective groups and governments. An example of this is the effects of global warming upon Pacific nations that may be swamped by searise (2003: p. 321-337) [13].

Indeed, many small islands in the Caribbean, Indian Ocean and Pacific Ocean are highly vulnerable to sea-level rise and may even be unliveable or destroyed by relatively small rises. This is clear example of a wicked problem as it involves great uncertainties, is somewhat unknowable in traditional research terms and involves natural, cultural and social systems. Jon Barnett and Neil Adger [14] call this "cognitive uncertainty" and 
cite it as a definitive aspect of a wicked problem. They also state that another intrinsic element is "strategic uncertainty" by which they mean that, as many participants are involved, there is no single clear line of thought or scholarly systematic thinking to follow. As many strategies arise from the opinions, ideas and actions of many enactors, they see that "diverging and conflicting strategies are the result, and may cause stagnation and deadlocks in policy debates-they may also lead to surprising and unexpected outcomes". Their third uncertainty basic to wicked problems is "institutional uncertainty" which they ascribe to fragmentation of policy networks and institutional, regional and local ideas, influences, opinions and reactions. To overcome such fragmentation and to facilitate research on such wicked problems, they look to facilitating networks between stakeholders by applying policy network theory.

This involves recognising the multiple networks that prevail and interact in this increasingly complex networked world [9]. Ellen Van Beuren et al. [12] see these as rounds in a policy making/implementing/planning game that may occur simultaneously as well as at different times and present opportunities as well as meet impasses. Also, "breakthroughs may occur, which give the game new impulses and result in a crucial decision; these result in a new round of the policy game" (195).

Clearly this knowledge structure presents a challenge to traditional ways of knowing as enacted within most extant $\mathrm{PhD}$ models. The major reason for this is that networked knowledge looks at the procedures rather than the result or content of knowledge construction. It does not, thus, lead to a linear set of data considerations leading to a defined piece of knowledge. The intrinsically unstructured nature of policy games is based upon achieving collaboration, yet: "institutional barriers, cognitive differences, and the dynamics of the interactions themselves can block joint action and the undertaking of necessary network management strategies" (2011: p. 211) [12].

Wicked problems, then, provide an opportunity to develop the contemporary $\mathrm{PhD}$ model in scholarship because the initial research question is not definitive, singular nor able to be focussed, and scholars who may address them exist within a fluid and complex network rather than acting as knowledge solution agents. Their complexity may "engender a high level of conflict among the stakeholders", and hence lead to even more complexity [15]. When neither the problem nor a solution can be defined, Nancy Roberts says that "nothing really bounds the problem solving process-it is experienced as ambiguous, fluid, complex, political, and frustrating as hell. In short, it is wicked" (2000: p. 2). She suggests that we need to develop "coping strategies" that begin ... with the hope that there is a better way of doing things, a recognition that failure is possible, and a willingness to "trust the process" without guarantees of a particular outcome. It is sustained on personal reserves that enable people to remain calm and centred in the face of the unknown and the unknowable (16).

Brian Head sees that there are thus "new challenges for both researchers and practitioners in coming to grips with these issues" (2008: p. 101) [16]. He defines "wicked problems" as involving high complexity and multiple actions and interactions, not merely uncertainties nor value divergences. Moreover, "the effectiveness and longevity of traditional solutions may indeed be problematic" (105). Indeed, even the definition of a problem involves the possibility of a solution, particularly as “... problems are often 'nested' and interdependent. This feature raises great difficulties both for clear analysis and for devising practical interventions to tackle the problems" (107), much less reach solutions acceptable to policy makers or knowledge gatekeepers.

The complex uncertainties described by "wicked problems" contribute to thinking within the academy about the need for contemporary $\mathrm{PhD}$ models that relate to knowledge construction and research in or regarding society, industry and government. Head sees the importance of more research into "better knowledge, better consultation, and better use of third-partner parties" (114). To do so requires "new thinking about the multiple causes of problems, opening up new insights about the multiple pathways and levels required for better solutions, and gaining broad stakeholder acceptance of shared strategies and processes" (115).

Linear research techniques are dominated by Enlightenment models of knowledge construction. These are described by Jeff Conklin as a pattern of thinking that ascribes to the "waterfall" model that dominates industry organizational materials "because it suggests the image of a waterfall as the project 'flows' down the steps towards completion (2005: p. 5) [8]"; he critiques it and suggests another methodology: opportunity-driven and unpredictable leaps. The "waterfall" image is replaced by "the 'jagged' line" (6). Moreover, "this non-linear process is not a defect, but rather the mark of an intelligent and creative learning process", particularly when working on a complex project (7). He thus describes the waterfall as applicable when you already know, and the jagged line as describing the process undertaken to find out, and the latter as a necessary research technique regarding the "wicked problem". 


\section{The Rhizomatic}

Linear research traditionally uses the steps of data gathering, data analysing, solution reaching and solution implementation. Challenges to such models of knowledge production that don't seem to be readily called upon in the literature come from utilising theoretical prisms such as feminism and postmodernism that enable us to read against the grain of the givens. The laterality of working with wicked problems is not new in scholarship that discusses Jacques Derrida's "deconstruction" and "bricolage" or the rhizomatic nature of knowledge described by Deleuze and Guattari. Thinking, for them, can both deterritorialize and reterritorialize nets of connections or rhizomatic movements.

As wicked problems recognise social complexity, so they provide opportunities for different models of knowledge within PhD structures. Big data was the wicked problem of the early 21st century: now it's the ideas around imperceptible knowledge that may be addressed through assemblage (2005: p. 8) [17]. Assemblage is a concept addressing global knowledge concerns about how information, ideas, analyses and understandings can be seen to be in a state of continuous arrangement rather than reaching a focussed conclusion. The assemblage, then, is "a multiplicity with the ability of counter actualizing our present" (2005: p. 120) [17]. Instead of trying to solve a problem, this identifies the problematic and works with it.

In the context of the emergent contemporary PhD models, such assemblage does not rely upon or seek repetition as it builds upon (or takes rhizomatic slices of) the work of Deleuze and Guattari [18]. Such ideas include working within cultural changes, allowing for unpredictability and accepting rapid change in contemporary global societies whilst at the same time working towards definition and delineation. They are also applicable to creativity and PLR.

\section{Conclusions}

Wicked problems are far from static; nor do they lead in any linear or analytic way towards a conclusion. There is no objectivity in their conception, birth, pursuit and attempts at delivery, nor do they reside in one particular space and time [19]. They present a challenge to most established models of $\mathrm{PhD}$ production in that there is neither singular question nor rationality leading to a solution, and there is much struggle in between! Their presence, however, is electrifying, dynamic and contemporary, offering many opportunities for scholarship to interact with creative industries, general industry, government and commerce in a global world that appears singular but arises from diverse social, cultural and personal value systems.

In this context, it is inevitable that we should see wicked problems as offering new pathways for scholarship often from and within non-academic spaces: this is most rhizomatic. For Deleuze and Guattari (1988) [18]: assemblages provide plateaux and rhizomes that are "any multiplicity connected to other multiplicities by superficial underground stems in such a way as to form or extend a rhizome" (22).

The paradox inherent in the term "wicked problems" is that they arise in the global culture in which we live that is inevitably complex and without linearity or focussed solutions. Another way of looking at them, then, is to see them as gifts to scholarship opening up pathways, ideas and knowledge that might otherwise not meet the extant traditional or even creative PhD models.

In the ever-faster moving 21 st century, the ability to try something, especially something new, is central to both meeting and sustaining the speed of change:

Suppose that we consider the possibility that there is more to our world than we can perceive, and more than we can conceive. Suppose the world overflows the categories of representation that the dogmatic image of thought imposes on it. This is not to say that our particular categories are lacking something that other, better categories would give us. Our imaginations must go further than that. We need to consider the possibility that the world... outruns any categories we might use to capture it [11].

In this paper I have brought to the discussion of wicked problems and creativity as two aspects of the contemporary PhD. I have suggested that looking at both gains new insights into scholarship about this most privileged area of teaching and learning within the academy.

\section{References}

[1] (2013) The Changing PhD Group of Eight Discussion Paper March.

[2] (2014) AQF. www.aqf.edu.au/ 
[3] Copeliovitch, A. (2015) The Actor, the Pilgrim and the Fieldpath.

[4] Grierson, E. and Brearley, L. (2009) Creative Arts Research. Narratives of Methodologies and Practices. Sense Publishers, The Netherlands.

[5] Brown, V.A., Harris, J.A. and Russell, J.Y. (2010) Tackling Wicked Problems through the Transdisciplinary Imagination. Earthscan.

[6] Fischer, F. (2015) From Theory to Practice. Readings in Planning Theory, 348.

[7] Sorensen, B. (2005) Immaculate Defection: Gilles Deleuze and Felix Guattari in Organization Theory. The Sociological Review, 53, 120-133. http://dx.doi.org/10.1111/j.1467-954X.2005.00545.x

[8] Conklin, J. (2005) Dialogue Mapping: Building Shared Understanding of Wicked Problems. John Wiley \& Sons, Inc., Hoboken.

[9] Enroth, H. (2011) Policy Network Theory. The Sage Handbook of Governance. 19-35.

[10] Rinne, K. and Sivenius, P. (2007) Rigorous Science-Artistic Freedom. The Challenge of Thesis Supervision in an Art University. South African Journal of Higher Education, 21.

[11] May, T. (2005) Gilles Deleuze: An Introduction. Cambridge University Press, Cambridge. http://dx.doi.org/10.1017/CBO9781139165419

[12] Van Bueren, E.M., Klijn, E.H. and Koppenjan, J.F. (2003) Dealing with Wicked Problems in Networks: Analysing an Environmental Debate from a Network Perspective. Journal of Public Administration Research and Theory, 13, 193 212. http://dx.doi.org/10.1093/jopart/mug017

[13] McCarthy, J.J. (2001) Climate Change 2001: Impacts, Adaptation, and Vulnerability: Contribution of Working Group II to the Third Assessment Report of the Intergovernmental Panel on Climate Change. Cambridge University Press, Cambridge.

[14] Barnett, J. and Neil Adger, W. (2003) Climate Dangers and Atoll Countries. Climatic Change, 61, 321-337. http://dx.doi.org/10.1023/B:CLIM.0000004559.08755.88

[15] NSW Creative Industry Economic Fundamentals.

[16] Head, B. (2008) Wicked Problems in Public Policy. Public Policy, 3, 101-118.

[17] Roberts, N. (2000) Wicked Problems and Network Approaches to Resolution. International Public Management Review, 1, 1-19.

[18] Deleuze, G. and Guattari, F. (1988) A Thousand Plateaus: Capitalism and Schizophrenia. Athlone Press, London.

[19] Coyne, R. (2005) Wicked Problems Revisited. Design Studies, 26, 5-17. http://dx.doi.org/10.1016/j.destud.2004.06.005

\section{Submit or recommend next manuscript to SCIRP and we will provide best service for you:}

Accepting pre-submission inquiries through Email, Facebook, LinkedIn, Twitter, etc.

A wide selection of journals (inclusive of 9 subjects, more than 200 journals)

Providing 24-hour high-quality service

User-friendly online submission system

Fair and swift peer-review system

Efficient typesetting and proofreading procedure

Display of the result of downloads and visits, as well as the number of cited articles

Maximum dissemination of your research work

Submit your manuscript at: http://papersubmission.scirp.org/ 